\title{
IMPACT OF E-LEARNING EDUCATION INTERVENTION ON NUTRITION AND EALTH PRACTICES OF RURAL WOMEN, IT'S CORRELATION AND PREDICTION WITH SOCIO ECONOMIC AND DEMOGRAPHIC VARIABLES
}

\author{
NIDA FATIMA HAZARI ${ }^{1} \&$ V. VIJAYA LAKSHMI ${ }^{2}$ \\ ${ }^{1}$ PhD, Department of Foods \& Nutrition College of Home Science, PJTSAU, Hyderabad, India \\ ${ }^{2}$ Professor \& Head, Department of Foods \& Nutrition, College of Home Science, PJTSAU, Hyderabad, India
}

\begin{abstract}
The purpose of this study was to determine the impact of e-learning education intervention, on nutrition and health practices of rural women, before and after receiving intervention for a period of 6 months. A total of 100 rural women from three rural villages of Telangana, India were randomly selected. A validated questionnaire was used to assess the practice of pre and post intervention. Correlation matrices were computed between the independent variables and pre-post practice scores. It was also established using multiple regression models, on which variables have effects on practices. It was seen that, age was found to be positively and highly significant before intervention. Education and occupation were shown to be negatively significant, with the pre practice scores. Post intervention for only age and family type, showed a positive significant relationship, whereas occupation revealed a negative but highly significant relationship. The findings explained that occupation, type of family, income and urban contact had high significance and independent effects $(P<0.01)$. It can be explained that, nutrition and health practices of rural women, even at a very basic level plays an important role in shaping them towards their own good health and nutritional status.

KEYWORDS: Nutrition and Health Practices, Socio-Economic and Demographic Variables \& E-Learning
\end{abstract}

Received: Sep 05, 2017; Accepted: Sep 30, 2017; Published: Oct 14, 2017; Paper Id.: IJESROCT201715

\section{INTRODUCTION}

Women play an important role within the household and are responsible for water supply, environmental and personal hygiene, food distribution and preventive health activities. These practices of the mother might be influenced by innumerable factors, influenced mainly by local tradition and culture. Thus, practice can be defined as the application of rules and knowledge, that leads to good action. Good practice is an art that is linked to the progress of knowledge and technology, and is executed in an ethical manner. Today is the era of Information technology, which is one of the most powerful enablers, facilitating learning and teaching to take place beyond the traditional boundaries.

\section{Socio - Economic and Demographic Factors in Relation to Nutrition and Health Practice}

Nutrition is a fundamental pillar of human life, health and development, throughout the entire life span (World Bank, 2006). Proper food and good nutrition are essential for survival, physical growth, mental development, performance and productivity, health and well - being. The promotion of women's health and other preventive health care practice should start before birth, during intrauterine life and extends throughout different phases of their lives, in order to sustain their general as well as their reproductive health, in general (Nagiebs, 
2003).

Socio - economic status has been defined as the position that, an individual or family occupies with reference to the prevailing standards of cultural possessions, effective income, material possessions and participation in the group activities of the community (Chapin, 1928).

It is often found that, the women are the vulnerable section of the society, relative to their male counterparts and they often happen to be the last receivers of the opportunities, delivered along with the development of the nation. Low health literacy has been associated with lower socio - economic status, living outside major cities, having less formal education, not able to speak English and not being employed (Australian Bureau of Statistics, 2006).

The rural health disadvantage is related to socio - economic factors, such as low income and low education levels, geographic isolation from services, health service and workforce shortage, and high per capita cost of delivering services, to sparsely distributed populations.

Age

A local study in Ethiopia showed that, women in the youngest age group (15 - 19 years) and women in the oldest age group surveyed (45 - 49 years) are the most affected by under - nutrition (Teller and Yimar, 2000).

\section{Marital Status}

Marital status of the woman is associated with household headship, and other social and economic status of the women that affect their nutritional status. Nutritional and social securities could be endangered by a negative change, in marital status.

\section{Education}

Education is an important socio - economic characteristic, as educational attainment often affects reproductive behavior and health practices of the individuals. It is an essential prerequisite of all round development of individuals, toward a better quality of life. Bharati et al. (2008), also reported that educational qualification is a key determinant of nutritional status in Indian women It is a well - established fact that a more educated mother or caregiver raises a better quality child than a less educated mother (UNICEF, 2001).

\section{Occupation}

The occupation of a person is an important indicator, to determine the economic status of that person in a society. Hobbs and Blanks (1975) submitted that, occupation plays a major role in shaping the lifestyles. According to them, it increases women's access to resources and strengthens their bargaining power, within the household and the workplace.

\section{Family Type}

Family is a universal social institution. Eliot and Gray (2000) stated that, all family set ups bear a strong relationship, that influences the life patterns of their members.

\section{Income}

Income is likely to mirror the availability of economic and material resources and therefore, influence the dietary quality by making healthy food more or less affordable and accessible. It is strongly correlated with health status and 
access to health care. Nakahara et al. (2006) suggested that, in many developing countries, the poor women had multiple roles, and that often their time constraints were so severe, that their participation in the income-generating activities resulted in a reduced childcare time, which in turn affected the children's health.

\section{Audio - Visual Material Possession}

A measure of the types and number of different household material a family owns maybe a fairly good indicator, of family prosperity. Earlier radio played a significant role in reaching, informing and educating people, and was a dominant medium with wide access, but today's computers and internet have influenced the way we learn and all these media are very powerful to reach, teach and enrich knowledge of people.

Moore and Tait (2002), focusing on the use of new communication technology, in distance education systems such as e - learning, stated that educators and trainers gave up working with radio categorizing it, as a low educational tool.

\section{Mass Media Exposure}

Dramatic changes in communication technology have occurred, in developing regions of the world. Mass media exposure refers to the availability of radio, television and print media. Mass Media play an important role in providing nutrition education to the masses, particularly to the women in a specially designed program, for the rural population.

\section{Urban Contact}

Kivlin et al. (1971), defined urban contact as a communication variable in two ways. Firstly, by bringing the individual and through him the village into direct contact, with agencies of change, whose headquarters are in towns and cities. Secondly, by indirectly urbanizing the individual and his village, making more freedom of mobility and choice, and lessening the social pressure for conformity.

\section{MATERIALS AND METHODS}

The present study depicts the impact of e-learning education intervention on nutrition and health practices of rural women, before and after receiving intervention for a period of 6 months. A total of 100 rural women from three rural villages of Telangana, India were randomly selected. A validated questionnaire was used to assess the practice of pre and post intervention. Correlation matrices were computed between the independent variables and pre- post practice scores.

Data on socio-economic and demographic characteristics of rural women was collected through structured interview schedule and observation. A standardized questionnaire was developed to measure the respondent's nutrition and health practices. Since, rural women lack computer literacy the e-learning education material was developed, using $2 \mathrm{D}$ animation.

Correlation matrices were worked out with all the nine independent variables and practices, to determine the relative degree to which the socio-economic and demographic variables, contribute to variation in nutrition and health practices.

\section{Profile Analysis of the Respondents}

Women are the integral part of family and vital force in the socio - economic progress. They play a crucial role in the economic welfare of the family and perform different tasks, depending on their socio - economic structure, number of 
people in the family, the nature of professions they are involved in, and many other factors (Reddy and Narayan, 1987). Thus, in this section the rural women were classified into groups, on the basis of their personal and socio-economic characteristics viz., age, marital status, education, family type, occupation, income, audio - visual material possession, mass media exposure and urban contact.

Table 1: Distribution of Respondents According to Their Profile Characteristics are furnished in Table 1

\begin{tabular}{|c|c|c|c|c|}
\hline \multirow[t]{2}{*}{ S. No } & \multirow[t]{2}{*}{ Variable } & \multirow[t]{2}{*}{ Category } & \multicolumn{2}{|c|}{$\begin{array}{c}\begin{array}{c}\text { Experimental Group } \\
n=100\end{array} \\
\end{array}$} \\
\hline & & & $\mathrm{F}$ & $\%$ \\
\hline \multirow[t]{3}{*}{1} & Young women & $15-25$ years & 40 & 40 \\
\hline & Middle aged women & 26-35 years & 44 & 44 \\
\hline & Old women & $36-49$ years & 16 & 16 \\
\hline \multirow[t]{2}{*}{2} & Marital status & Married & 82 & 82 \\
\hline & & Unmarried & 18 & 18 \\
\hline \multirow[t]{5}{*}{3} & Education & Illiterate & 15 & 15 \\
\hline & & primary school & 14 & 14 \\
\hline & & middle school & 8 & 8 \\
\hline & & high school & 48 & 48 \\
\hline & & College & 15 & 15 \\
\hline \multirow[t]{3}{*}{4} & Occupation & house wife & 81 & 81 \\
\hline & & working women & 8 & 8 \\
\hline & & Student & 11 & 11 \\
\hline \multirow[t]{2}{*}{5} & Family type & Nuclear & 55 & 55 \\
\hline & & Joint & 45 & 45 \\
\hline \multirow[t]{4}{*}{6} & Income -poor & upto 2000 & 2 & 2 \\
\hline & -low & $2000-5000$ & 39 & 39 \\
\hline & -medium & $5000-10000$ & 40 & 40 \\
\hline & -high & $>10000$ & 19 & 19 \\
\hline \multirow[t]{3}{*}{7} & Possession of Audio-visual material & Television & 51 & 51 \\
\hline & & Mobile & 36 & 36 \\
\hline & & CD Player/Laptop & 13 & 13 \\
\hline \multirow[t]{3}{*}{8} & Mass media exposure & Never & 2 & 2 \\
\hline & & occasional & 2 & 2 \\
\hline & & daily & 96 & 96 \\
\hline \multirow[t]{2}{*}{9.} & Urban contact & Medium & 77 & 77 \\
\hline & & High & 23 & 23 \\
\hline
\end{tabular}

\section{RESULTS}

The results of the present study, was on the impact of e-learning education intervention on nutrition and health practices of rural women, its correlation and prediction with socio economic and demographic variables.

Table 2: Correlation Coefficient between Socio - Economic and Demographic Variables and Nutrition and Health Practices

\begin{tabular}{|l|c|c|}
\hline \multicolumn{1}{|c|}{ Variable } & $\begin{array}{c}\text { Correlation Coefficient } \\
\text { Pre-Practice }\end{array}$ & $\begin{array}{c}\text { Correlation Coefficient } \\
\text { Post-Practice }\end{array}$ \\
\hline Age & $0.35^{* *}$ & $0.24^{*}$ \\
\hline Marital status & $0.1^{\mathrm{ns}}$ & $-0.15^{\mathrm{ns}}$ \\
\hline Education & $-0.23^{*}$ & $-0.14^{\mathrm{ns}}$ \\
\hline Occupation & $-0.23^{*}$ & $-0.22^{*}$ \\
\hline Family type & $0.15^{\mathrm{ns}}$ & $0.2^{*}$ \\
\hline Annual income & $-0.07^{\mathrm{ns}}$ & $0.2^{\mathrm{ns}}$ \\
\hline Material possession & $-0.03^{\mathrm{ns}}$ & $0.15^{\mathrm{ns}}$ \\
\hline
\end{tabular}



It's Correlation and Prediction with Socio Economic and Demographic Variables

\begin{tabular}{|l|l|l|}
\hline Mass media exposure & $0.03 \mathrm{~ns}$ & $0.14^{\mathrm{ns}}$ \\
\hline Urban contact & $-0.12^{\mathrm{ns}}$ & $-0.08^{\mathrm{ns}}$ \\
\hline
\end{tabular}

Table 3: Socio - Economic and Demographic Variables Contributing Significantly to Nutrition and Health Practices

\begin{tabular}{|c|c|c|c|c|}
\hline $\begin{array}{l}\text { Variables } \\
\text { Remained }\end{array}$ & $\begin{array}{l}\text { Partial Reg. co-ef. } \\
\text { (b-Values) }\end{array}$ & $\begin{array}{l}\text { S.E. of } \\
\text { 'B' }\end{array}$ & $\begin{array}{c}\text { T Value of } \\
\text { 'B' }\end{array}$ & $\begin{array}{c}\% \\
\text { Contribution }\end{array}$ \\
\hline Occupation & -0.3970 & 0.157 & $-2.52 * *$ & 21.62 \\
\hline Family type & 0.7154 & 0.300 & $2.38 * *$ & 18.01 \\
\hline Income & 1.022 & 0.266 & $3.84 * *$ & 24.62 \\
\hline Urban contact & -1.465 & 0.492 & $-2.98 * *$ & 35.74 \\
\hline \multicolumn{5}{|c|}{ Intercept $=30.66: \mathrm{R}^{2}=0.21$} \\
\hline \multicolumn{5}{|c|}{ * Significant at 5 per cent level } \\
\hline
\end{tabular}

\section{DISCUSSIONS}

The tremendous development in Information and Communication technologies (ICT's) has paved the way for e learning. The Socio - economic status of women plays a vital role in both individual and community life. Nutrition and health practices measured, where personal hygiene of the respondent, household and environmental sanitation and utilization of major and other community services, along with special emphasis on the immunization of children (1 - 6 years), using a validated questionnaire pre and post e-learning educational intervention.

Age, marital status, education, occupation, family type, income, audio - visual material possession, mass media exposure and urban contact were the socio - economic demographic variables studied.

Increasing the level of education also implies adoption of modern ideas, while gradually leading to the dereliction of traditional practices, regarding child care. A study conducted in Nigeria showed that, mothers' educational level and occupation influenced both time and duration of breast feeding and introduction of milk formula (Igbedioh, 1996).

The maternal employment and the educational characteristics became a constraint for the well child - care practices, as the alternative caregivers took over a more important role in the child care, as the mothers join the workforce (Kulwa et al. 2006). Educational level was associated with good practices.

According to table 2, age, education and income were significantly, correlated with practice score among rural women (Aruna et al. 2013). Participants who had completed higher secondary and secondary education were found to have a better practice, compared to the illiterate group (Dhimal et al. 2014).

The correlation between socioeconomic and demographic variables and pre-post practice scores, as shown in the table 2 revealed that, the Age of the respondents was found to be positively and highly significant, with the practice score before educational intervention and education and occupation were shown to be negatively significant with the pre practice score.

After educational intervention, only age and family type showed a positive significant relationship, whereas occupation revealed a negative, but a highly significant relationship with the post - practice score, as shown in the table 2 . Hygiene practice is another factor that can greatly affect the status of the children and thus, it was gathered from the data that many of the mothers with little nutrition education did not always care about the safety of their food, whereby it may 
be an avenue for different organism causing disease to grow, which will affect the health status of the child at the end.

In the present research, as shown in the table 2, it can be seen that, the pre and post practice scores showed significant association with the educational level and occupation of the respondents. Education and occupation were positively significant with pre intervention practice scores, but post intervention practice scores revealed negative, but highly significant relationship with which it can be inferred that, as the women's involvement in the occupational activity increased, the practice level was decreasing may be due to lack of sufficient time, to implement the knowledge gained.

In order to establish whether the socio - economic and demographic variables were all having separate effects on knowledge, these variables were entered into a multiple regression model. The outcome of the final regression equation, on analyzing the most significantly effecting socio - economic and demographic variables on nutrition and health practices is presented in table 2 .

The results showed that occupation, family type, income and urban contact all and had high significance and independent effects, at 0.01 levels. Together, these variables accounted for 21 percent in practice score.

Dhimal et al. (2014), found a significant association between prevention practices and the educational levels of the participants, in a community based knowledge, attitude and practices study of dengue fever in Nepal. Educational level was associated with good practices and practice in the community is influenced, mainly by local tradition and culture. Sillah et al. (2013), concluded that, higher maternal age and socio - economic status was correlated with higher practice and KAP scores. Age, education, income was significantly, correlated with practice score among rural women (Aruna et al. 2013).

Education level only was a significant predictor of practice level. Participants, who had completed higher secondary education and secondary education, were found to have a better practice compared to the illiterate group (Dhimal et al. 2014).

\section{CONCLUSIONS}

The results support the likely value of including educating on best practices, as a target for good health education aimed at promoting healthy eating. It has been observed that, undesirable attitude or health practice may persist, inspite of correcting practices regarding adequate nutrition. The women continue to practice such behavior because, they are insensitive to change and that, understanding is not necessarily followed by change. This may be attributed to the strong believed cultural factors and dietary habits. Thus, the use of Information, communication technology in the education sector is a practice, that can no longer be ignored and which has led to the emergence of a new concept of e - learning, which uses ICT to support the education system of formal, non-formal and informal education and lifelong learning.

\section{REFERENCE}

1. Aruna, R. T., Sarojani, J. K., Pushpa Bharati. 2013. Impact of education intervention on knowledge regarding iodine deficiency disorder. Karnataka Journal. Agric. Sci, 26 (1) : 124 - 127.

2. Bharati, P., Som, S., Chakrabarty, S. , Bharati, S and Pal, M. 2008. Prevalence of anemia and its determinants among nonpregnant and pregnant women in India. Asia-Pacific Journal of Public Health, 20(4): 347-355.

3. Chapin, F. 1928. A Quantitative Scale for Rating the Home and Social Environment of Middle Class Families in an Urban Community. Jour. Educ. Psych. 19, $99-111$. 
4. Dhimal, M., Aryal, K.K., Dhimal, M.L. 2014. Knowledge, Attitude and Practice regarding Dengue fever among the healthy population of Highland and Lowland communities in Central Nepal. Plos. ONE 9 (7).

5. Elliott, S and Gray, A. 2000. Family Structures. A Report for the New Zealand Immigration Service.

6. Hobbs, D.A., Blank, S.J. 1975. Sociology and the Human Experience. John Wiley Incorporation.

7. Iqbedioh, S.O., Oqbeni, A.O., Adole, G.M.1996. Infant weaning practices of some Tiv women resident in Mkurdi, Nigeria. Nutr Health 11 (1): $13-28$.

8. Kivlin. 1971. Conceptual framework. Rural Women: Management in farm and home. A. Laxmi Devi. Northern Book Centre. Daryagunj. New Delhi. $p-18$

9. Kulwa,K. B., Kinabo, J. L., Modest, B. 2006. Constraints on good child care practices and nutritional status in urban Dar - es - Salaam, Tanzania. Food Nutr Bull. Sep; 27 (3) : $236-44$.

10. Moore, P. E and Tait, A . 2002. Open and Distance learning: Trends, Policy and Strategy Considerations. Paris: UNESCO.

11. Nakahara, S., Poudel, K.C., Lopchan, M.,Ichikawa, M., Tandukar, K.P., Jimba. M. 2006. The availability of the childcare support and the nutritional status of the children of non-working and working mothers in urban Nepal. American Journal of Human Biology. 18(2):169-81.

12. Nagiebs, S. 2003. Nutrition during maternity cycle; Review article, University of Assiut, Faculty of Nursing. Pp.18-22.

13. Reddy, G.Nand Reddy, Suna, Narayana. 1987. Women and Child Development. Allahabad: Chugh Publishing House.

14. Sillah, F., Ho, H. J and Chao, J. C. 2013. The use of oral rehydration salt in managing children under 5 year old with diarrhea in the Gambia: knowledge, attitude, and practice. Nutrition. Nov - Dec; 29 (11 - 12) : 1368 - 73.

15. Teller, H., and G, Yimar. 2000. Levels and determinants of malnutrition in adolescent and adult women in southern Ethiopia. Ethiopian Journal of Health Development. 14 (1): 57-66.

16. World Bank, (2006). Repositioning Nutrition as central to development: A strategy for large scale action, The International Bank for Reconstruction and Development, World Bank, Washington DC.

17. UNICEF/Nigeria. 2001. Federal government of Nigeria and UNICEF master plan of operations for a country program of cooperation for Nigerian children and women-2002-2007. Lagos: United Nations Children's Fund.

18. Australian Bureau of Statistics. 2006. Adult Literacy and Life Skills Survey, summary results, Australia. Canberra: ABS, 2007. 
